J. Lake Sci. (湖泊科学), 2014, 26(2): 207-212

http: //www. jlakes. org. E-mail : jlakes@niglas.ac.cn

(c) 2014 by Journal of Lake Sciences

\title{
望虞河引长江水入太湖水体的总磷、总氮分析"
}

\author{
马 倩 $^{1}$, 田 威 ${ }^{1}$, 吴朝明 ${ }^{2}$ \\ (1: 江苏省水文水资源勘测局,南京 210029) \\ （2：江苏省水文水资源勘测局无锡分局,无锡 214031）
}

摘 要: 太湖流域实施的调水引流, 提高了流域水资源和水环境承载能力, 发挥了水利工程在改善水环境方面的综合效 益, 支撑了流域经济社会的可持续发展. 本文在分析近年来望虞河引江水量与人湖水量及人湖水体流经太湖湖湾水体水 质变化情势的基础上, 分析比较了 2007 年以来的调水引流期间, 望虞河人太湖水体总磷、总氮浓度值与太湖贡湖湾、梅梁 湾、湖西及江苏省其它主要人太湖河道的总磷、总氮浓度值, 并通过监测结果分析了人太湖水体总磷、可溶性总磷的衰减 趋势, 从而得出, 长江是优质水源, 调引长江水为增加太湖水环境容量、改善太湖及区域水环境状况起到了积极作用.

关键词 : 总磷; 总氮; 调水引流;望虞河;太湖

\section{Total phosphorus and total nitrogen concentrations of the water diverted from Yangtze River to Lake Taihu through Wangyu River}

\author{
MA Qian ${ }^{1}$, TIAN Wei ${ }^{1} \&$ WU Zhaoming ${ }^{2}$ \\ (1: Hydrology and Water Resources Investigation Bureau of Jiangsu Province, Nanjing 210029, P. R. China) \\ (2: Wuxi Branch of Hydrology and Water Resources Investigation Bureau of Jiangsu Province, Wuxi 214031, P. R. China)
}

\begin{abstract}
The water diversion implemented in Lake Taihu basin has improved the carrying capacity of water resource and water environment, and expressed the comprehensive benefit of hydraulic engineering to the improvement of water environment. It supported the sustainable development of social economy in Lake Taihu basin. Based on the trend analyses of intake and input water quantity in Wangyu River, and the water quality when the input water running through the Lake Taihu in recent years, this paper compares the total phosphorus and total nitrogen concentrations of input water with that of Gonghu Bay, Meiliang Bay, west lake bay and other main input rivers during the period when Yangtze-Taihu water diversion began since 2007. By analyzing the attenuation trends of the total phosphorus and total dissoluble phosphorus concentrations during water diversion period based on the monitoring results, it is illustrated that the Yangtze River had high quality water, and Yangtze-Taihu water diversion has played a positive role in increasing the capacity of water environment and improving the water environment of Lake Taihu.
\end{abstract}

Keywords: Total phosphorus; total nitrogen; Yangtze-Taihu water diversion; Wangyu River; Lake Taihu

2002 年根据太湖流域水环境治理的需求, 水利部太湖流域管理局组织江苏、浙江、上海两省一市水利部 门启动“引江济太”调水试验工程. 2007 年太湖贡湖湾发生供水危机后, 江苏省果断开启梅梁河原站, 在原 “引江济太”调水线路望虞河一东太湖一太浦河的基础上, 又增加了望虞河一贡湖湾一梅梁湾一五里湖一梁溪河 的调水线路 (图 1). 有文献指出,2007 年无锡发生供水危机后, 随着“引江济太”调水工程的进行, 贡湖湾、小 湾里、锡东水厂水源地水质好转 ${ }^{[-2]}$. 近年来调水引流工程合理调控了太湖水位、改善了人湖水质、有效减少 了湖体内源污染、保障了流域供水安全 ${ }^{[34]}$,形成了发挥治太骨干工程效益、统一调度和优化配置流域水资 源、应急改善流域水环境的调水引流线路 ${ }^{[5]}$. 目前已有研究表明, 太湖西部人湖河道水体全年总氮含量监测 值均劣于 V 类水指标, 水体的富营养化主要体现为总氮含量超标 ${ }^{[6]}$, 从望虞河引长江水人太湖水体水质浓

* 水利部公益性行业科研专项项目(201301041) 和国家水体污染控制与治理科技重大专项项目 (2012ZX07101-010) 联合资助. 2013-03-12 收稿;2013-09-30 收修改稿. 马倩 (1961 ), 女,教授级高级工程师; E-mail: maq210029 @ aliyun. com. 


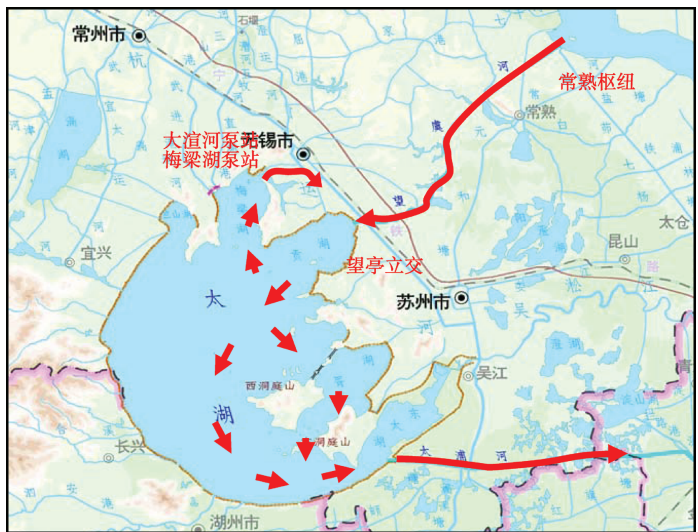

图 1 调水引流水流向示意图

Fig. 1 The sketch map of the flow of the water diversion

度升高的幅度与调水流量的大小呈反比 ${ }^{[7]}$, 太湖 主要人湖河道多年平均人湖污染物量约占江苏环 湖人湖量的 $90 \%{ }^{[8-10]}$. 本文应用江苏省水文水资 源勘测局及无锡分局近年来的监测结果, 分析望 虞河近年调水量及太湖北部湖湾水质变化情势, 分析比较调水引流期间望虞河调引长江水的人湖 水体总磷、总氮浓度值与人太湖主要河道及太湖 贡湖湾、梅梁湾、湖西的总磷和总氮浓度差异, 分 析望虞河人湖水体总磷、可溶性总磷的衰减趋势.

\section{1 望虞河近年调水概况及太湖湖湾水体水 质分析}

望虞河位于太湖流域北部, 是流域综合治理 骨干工程之一, 总长 $60.8 \mathrm{~km}$, 既是流域洪水外排 长江的主要河道, 又是目前唯一一条将长江水源 直接引人太湖的通道. 望虞河人湖、人江口分别设有望亭水利枢纽和常熟水利枢纽; 望虞河东岸支河口门已 基本控制, 西岸支河口门为兼排地区涝水, 仅北部靠近长江的福山塘以北段和南部嘉菱荡以南部分支河控 制外, 其余均为敞开; 调水过程中, 望虞河东岸闸门的引水流量以不得超过调引江水量的 30\% 或最大引水流 量不超过 $40 \mathrm{~m}^{3} / \mathrm{s}$ 控制, 望虞河常熟枢纽调引的长江水绝大部分流人太湖和西岸支流.

\section{1 望虞河引江及入湖水量}

根据江苏省水文水资源勘测局的监测资料分析,2002-2011 年共引长江水 $202.3 \times 10^{8} \mathrm{~m}^{3}$, 其中 $111 \times$ $10^{8} \mathrm{~m}^{3}$ 进人望虞河两岸的河网、91. $3 \times 10^{8} \mathrm{~m}^{3}$ 进人太湖; $2002-2011$ 年, 平均年引长江水 $20.2 \times 10^{8} \mathrm{~m}^{3}$, 平均年 人湖水量为 $9.1 \times 10^{8} \mathrm{~m}^{3}$. 几年来的人湖水量相当于太湖正常水位下水量的两倍, 同时使受益区河网水体基 本被置换. 多年来, 望虞河引江水量与人湖水量有增加的趋势 (图 $2 \mathrm{a}$ ), 且年均增长率分别为 $3.824 \%$ 和 $4.160 \%$, 人湖水量增加的幅度比引江水量增加的大; 多年的人湖效率 (人湖水量占引江水量的百分比) 均值 为 $45.1 \%, 2007$ 年人湖效率最高, 为 $55.9 \%, 2005$ 年人湖效率最低, 为 $20.6 \%$, 多年来, 人湖效率有缓慢增 长的趋势 (图 $2 \mathrm{~b}$ ), 年均增长率仅为 $0.463 \%$.
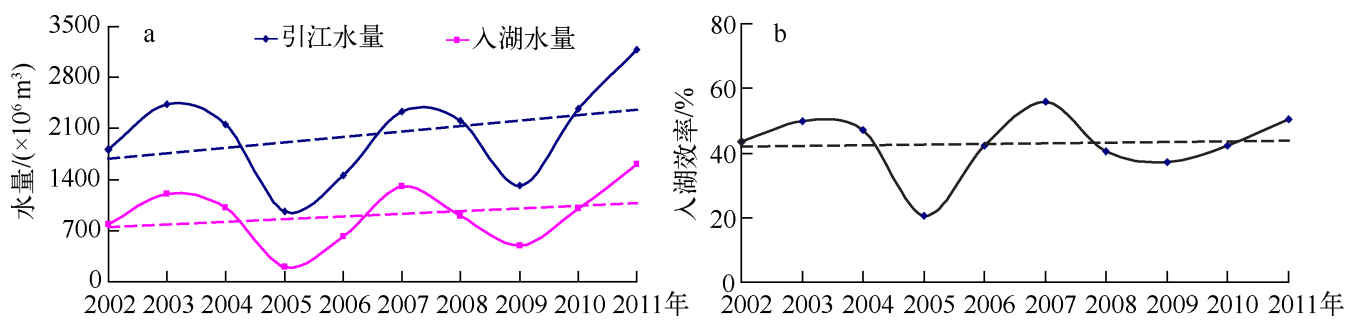

图 2 望虞河引江、人湖水量 $(\mathrm{a})$ 和人湖效率 $(\mathrm{b})$ 年变化过程

Fig. 2 Annual variation of intake and input water quantity(a) and input efficiency(b)

in Wangyu River during the period of water diversion

\section{$1.22009-2011$ 年调水实况及太湖主要湖湾水质状况}

2009-2011 年望虞闸共引长江水量 $68.7 \times 10^{8} \mathrm{~m}^{3}$, 其中 $37.7 \times 10^{8} \mathrm{~m}^{3}$ 进人望虞河两岸的河网、31. $0 \times$ $10^{8} \mathrm{~m}^{3}$ 进人太湖; 3 年中年均引江水量为 $22.9 \times 10^{8} \mathrm{~m}^{3}$, 年均人湖水量为 $10.3 \times 10^{8} \mathrm{~m}^{3}$, 比 $2002-2008$ 年年均 引江、人湖水量增加约 20\% . 在 2009-2011 年调水引流实践中,2011 年通过常熟枢纽引长江水量、通过望亭 立交枢纽江水人太湖量最多, 通过梅梁湾泵站、大渲河洜站排出太湖的水量也最多, 通过太浦闸出湖的水量 相对较少, 也就是说,2011 年是 2009-2011 年 3 年中太湖贡湖湾、梅梁湾水量交换较频繁的一年. 各年环太 
湖引排水工程引排水量见表 1 .

表 1 近年环太湖引排水工程引排水量

Tab. 1 The intake and input water quantities of the diversion around Lake Taihu in recent years

\begin{tabular}{|c|c|c|c|c|c|c|}
\hline \multirow{2}{*}{ 年份 } & \multicolumn{2}{|c|}{ 常熟枢纽 } & \multicolumn{2}{|c|}{ 望亭立交枢纽 } & \multirow{2}{*}{$\begin{array}{c}\text { 太浦闸出湖水量/ } \\
\left(\times 10^{4} \mathrm{~m}^{3}\right)\end{array}$} & \multirow{2}{*}{$\begin{array}{l}\text { 梅梁湾大渲河泵站 } \\
\text { 出湖水量 } /\left(\times 10^{4} \mathrm{~m}^{3}\right)\end{array}$} \\
\hline & 引水时间/d & 引水量 $/\left(\times 10^{4} \mathrm{~m}^{3}\right)$ & 引水时间/ $\mathrm{d}$ & 引水量 $/\left(\times 10^{4} \mathrm{~m}^{3}\right)$ & & \\
\hline 2009 & 121 & 13.19 & 63 & 4.89 & 20.37 & 4.75 \\
\hline 2010 & 222 & 23.72 & 151 & 10.04 & 38.43 & 6.77 \\
\hline 2011 & 252 & 31.86 & 219 & 16.08 & 18.42 & 6.93 \\
\hline
\end{tabular}

太湖流域水环境监测中心及江苏省水文水资源勘测局在太湖水域中较均匀布设 37 个监测点, 其中梅 梁湾 4 个、贡湖湾 4 个,监测频次为 1 次/月. 据分析,梅梁湾 2011 年年均氨氮浓度比 2009 、2010 年的分别下 降 $71.7 \%$ 、 $35.0 \%$, 总磷浓度分别下降 $37.0 \% 、 33.2 \%$; 贡湖湾 2011 年年均氨氮浓度比 2009 、2010 年分别下 降 28. 6\% 、 $11.8 \%$, 2011 年年均总磷浓度比 2009 年上升 $22.7 \%$, 比 2010 年下降 $10.8 \% .2009-2011$ 年太湖 北部主要湖湾水体年均水质参数值见表 2 . 从图 3 可以明显地看出, 梅梁湾、贡湖湾 2011 年的水质参数浓度 基本都处于最低,说明近年来实施的生态清淤 (2009-2011 年,清淤土方量约 $2100 \times 10^{4} \mathrm{~m}^{3}$ )、蓝藻打捞 (2009-2011 年,共打捞蓝藻约 $220 \times 10^{4} \mathrm{t}$ ) 及加大调水水量对改善梅梁湾、贡湖湾水质起到了一定的作用.

表 $22009-2011$ 年太湖主要湖湾水体年均水质参数值

Tab. 2 Annual water quality parameter values in main bays of Lake Taihu from 2009 to 2011

\begin{tabular}{|c|c|c|c|c|c|c|c|c|c|c|c|}
\hline \multirow[b]{2}{*}{ 湖湾 } & \multirow[b]{2}{*}{ 年份 } & \multicolumn{5}{|c|}{ 年均值 $/(\mathrm{mg} / \mathrm{L})$} & \multicolumn{5}{|c|}{ 评价值 } \\
\hline & & 溶解氧 & $\begin{array}{l}\text { 高锰酸 } \\
\text { 盐指数 }\end{array}$ & 氨氮 & 总磷 & 总氮 & 溶解氧 & $\begin{array}{l}\text { 高锰酸 } \\
\text { 盐指数 }\end{array}$ & 氨氮 & 总磷 & 总氮 \\
\hline \multirow[t]{3}{*}{ 梅梁湾 } & 2009 & 10.12 & 5.53 & 0.46 & 0.107 & 3.03 & I & III & II & $\mathrm{V}$ & $>\mathrm{V}$ \\
\hline & 2010 & 9.38 & 4.59 & 0.20 & 0.082 & 2.86 & I & III & II & IV & $>\mathrm{V}$ \\
\hline & 2011 & 9.17 & 4.62 & 0.13 & 0.066 & 1.91 & I & III & I & IV & V \\
\hline \multirow[t]{3}{*}{ 贡湖湾 } & 2009 & 10.10 & 3.72 & 0.21 & 0.053 & 1.54 & I & II & II & IV & V \\
\hline & 2010 & 9.53 & 3.77 & 0.17 & 0.056 & 2. 12 & I & II & II & IV & $>\mathrm{V}$ \\
\hline & 2011 & 9.09 & 3.34 & 0.15 & 0.052 & 1.89 & I & II & II & IV & V \\
\hline
\end{tabular}

\section{2 入太湖主要河道总磷、总氮浓度分析}

望虞河沿线望亭立交的水质监测站点设在望亭立交闸内,也就是说当望亭立交开闸引水时,其水质监 测站点水质代表从长江人太湖的水体水质状况，而当望亭立交关闸或排水时，其水质监测站点水质代表太 湖湖体水质; 太湖湖流流速缓慢, 太湖西面主要是人湖河道,东面主要是出湖河道,南北是出人性河道,一般 情况湖流是从东北向西南流动的; 根据江苏省水文水资源勘测局编写的《江苏省人太湖污染物总量分析》, 太湖湖西的主要人湖河道太滆运河、漕桥河、殷村港、陈东港的多年平均人湖水量约占江苏省河道人湖水量 的 $43 \%, 4$ 条河道多年平均的总氮人湖污染物量占江苏省河道的近 50\%. 江苏省环太湖出人湖河道 200 多 条,其中江苏省水文水资源勘测局每月 2 次水量水质同步监测的有 129 条河道,可见太滆运河、漕桥河、殷村 港、陈东港 4 条河道对太湖人湖水量与污染物的贡献. 江苏省水文水资源勘测局分别在太滆运河、漕桥河、 殷村港、陈东港的人太湖处布设水质监测断面,每月监测 1 次. 2007 年以来,在望亭立交引水期太湖湖西主 要人湖河道水体总磷平均浓度为 $0.300 \mathrm{mg} / \mathrm{L}$, 是望亭立交处水体总磷平均浓度 $(0.133 \mathrm{mg} / \mathrm{L})$ 的 2.26 倍, 除 殷村港有一次水体总磷浓度与望亭立交处的基本相当外,湖西主要人湖河道水体与望亭立交处水体总磷浓 度之比的变化幅度在 $1.10 \sim 3.12$ 之间, 望亭立交处水体总磷浓度明显小于太湖湖西主要人湖河道水体的总 磷浓度 (表 3) ; 在望亭立交开闸引水期中,太湖湖西主要人湖河道水体中总氮平均浓度为 $6.01 \mathrm{mg} / \mathrm{L}$, 是望 亭立交处水体总氮平均浓度 $(2.63 \mathrm{mg} / \mathrm{L})$ 的 2.29 倍, 湖西主要人湖河道水体与望亭立交处水体总氮浓度比 

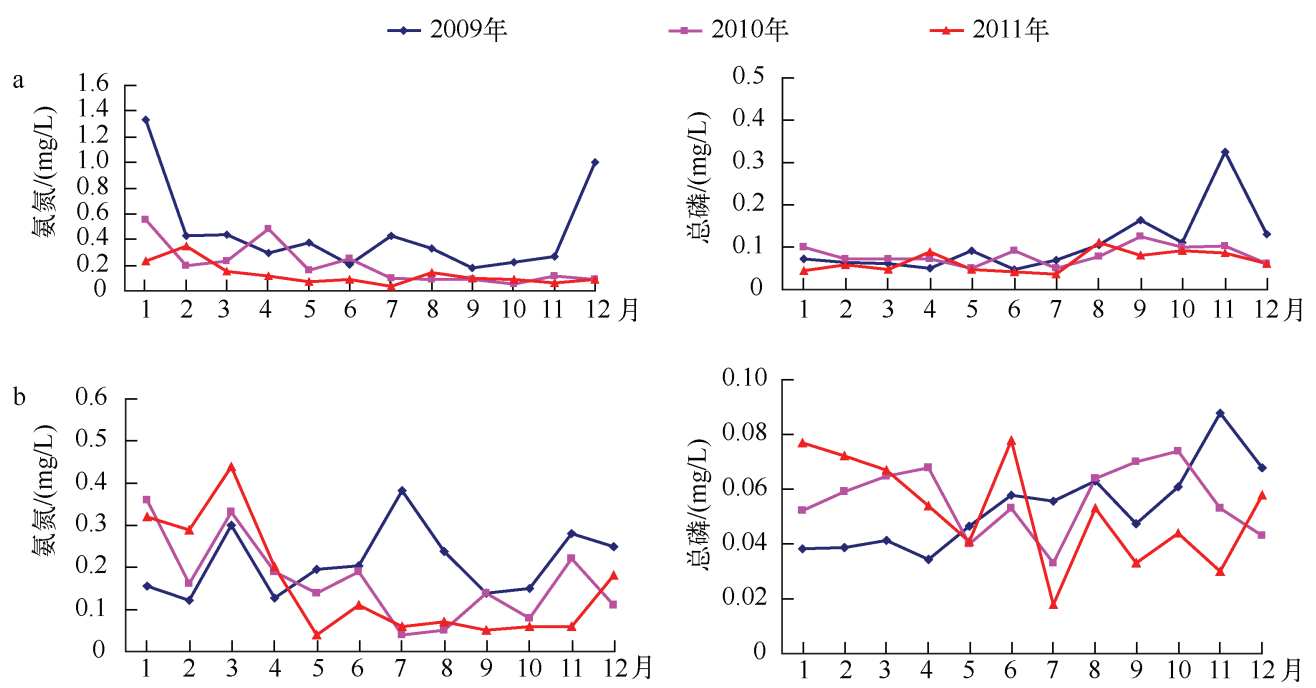

图 $32009-2011$ 年梅梁湾 (a) 和贡湖湾 (b) 水体水质参数浓度值变化

Fig. 3 Variation of water quality parameter concentrations

in Meiliang Bay(a) and Gonghu Bay(b) from 2009 to 2011

值的变化幅度在 $1.49 \sim 3.46$ 之间, 望亭立交处水体总氮浓度明显小于太湖湖西主要人湖河道水体的总磷浓 度 (表 4). 由此可见, 从望虞河引长江水人湖水体的总磷、总氮浓度比太湖湖西人湖水体的要低, 水质要好.

表 3 望亭立交引水期主要人湖河道总磷浓度

Tab. 3 Total phosphorus concentrations of the main input rivers during the period of water diversion

\begin{tabular}{|c|c|c|c|c|c|c|}
\hline \multirow{3}{*}{ 时段 } & \multirow{3}{*}{ 时间/d } & \multicolumn{5}{|c|}{ 总磷/( mg/L) } \\
\hline & & \multirow{2}{*}{$\begin{array}{c}\text { 望虞河 } \\
\text { 望亭立交 }\end{array}$} & \multicolumn{4}{|c|}{ 太湖湖西主要人湖河道 } \\
\hline & & & 太滆运河 & 漕桥河 & 殷村港 & 陈东港 \\
\hline 2007 年 5 月 11 日一 7 月 4 日 & 55 & 0.181 & 0.362 & 0.398 & 0.179 & 0.361 \\
\hline 2007 年 7 月 20 日一 9 月 18 日 & 61 & 0.114 & 0.320 & 0.350 & 0.126 & 0.296 \\
\hline 2008 年 1 月 22 日一 6 月 8 日 & 139 & 0.131 & 0.410 & 0.388 & 0.180 & 0.273 \\
\hline 2009 年 4 月 27 日一 6 月 28 日 & 63 & 0.123 & 0.278 & 0.360 & 0.256 & 0.244 \\
\hline 2010 年 5 月 31 日一 7 月 5 日 & 36 & 0.116 & 0.301 & 0.298 & 0.275 & 0.233 \\
\hline 2011 年 1 月 1 日一- 6 月 9 日 & 160 & 0.131 & 0.318 & 0.327 & 0.347 & 0.319 \\
\hline
\end{tabular}

\section{3 太湖湖湾总磷、总氮浓度分析}

根据太湖流域水环境监测中心及江苏省水文水资源勘测局的监测资料, 可以看出总磷的分布特点为: (1) 太湖湖西水体的总磷平均浓度为 $0.140 \mathrm{mg} / \mathrm{L}$, 是望亭立交处水体总磷平均浓度 $(0.132 \mathrm{mg} / \mathrm{L})$ 的 1.06 倍, 但湖西水体与望亭立交处水体总磷浓度比值的变化幅度在 $0.48 \sim 1.82$ 之间, 不同时段差异较大; (2)太湖梅 梁湾水体的总磷平均浓度为 $0.117 \mathrm{mg} / \mathrm{L}$, 仅是望亭立交处水体总磷平均浓度的 0.88 倍, 梅梁湾水体与望亭 立交处水体总磷浓度比值的变化幅度在 $0.43 \sim 1.99$ 之间, 不同时段的差异也较大; (3) 太湖贡湖湾水体的总 磷平均浓度为 $0.071 \mathrm{mg} / \mathrm{L}$, 仅为望亭立交处水体总磷平均浓度的 0.53 倍, 贡湖湾水体与望亭立交处水体总 磷浓度比值的变化幅度在 $0.41 \sim 0.73$ 之间, 太湖贡湖湾水体总磷浓度明显小于望亭立交处水体的(表 3 和 表 5 ). 总氮的分布特点为: (1) 太湖湖西水体的总氮平均浓度为 $4.57 \mathrm{mg} / \mathrm{L}$, 是望亭立交处水体总氮平均浓度 $(2.66 \mathrm{mg} / \mathrm{L})$ 的 1.72 倍, 湖西水体与望亭立交处水体总氮浓度比值的变化幅度在 $1.37 \sim 2.25$ 之间, 望亭立 交处水体总氮浓度小于湖西水体的; (2) 太湖梅梁湾水体的总氮平均浓度为 $3.56 \mathrm{mg} / \mathrm{L}$, 是望亭立交处水体 
总氮平均浓度的 1.34 倍,梅梁湾水体与望亭立交处水体总氮浓度比值的变化幅度在 $0.79 \sim 1.75$ 之间. 平均 来讲, 望亭立交处水体总氮浓度小于梅梁湾水体的, 但有时望亭立交处水体的总氮浓度要高于梅梁湾水体 的; (3) 太湖贡湖湾水体的总氮平均浓度为 $2.70 \mathrm{mg} / \mathrm{L}$, 仅比望亭立交处水体总氮平均浓度高 $0.04 \mathrm{mg} / \mathrm{L}$, 贡 湖湾水体与望亭立交处水体总氮浓度比值的变化幅度为 $0.93 \sim 1.19$, 有时望亭立交处水体的总氮浓度要略 高于贡湖湾水体的 (表 4 和表 5 ).

表 4 望亭立交引水期主要人湖河道总氮浓度

Tab. 4 Total nitrogen concentrations of the main input rivers during the period of water diversion

\begin{tabular}{|c|c|c|c|c|c|c|}
\hline \multirow{3}{*}{ 时段 } & \multirow{3}{*}{ 时间/d } & \multicolumn{5}{|c|}{ 总氮/(mg/L) } \\
\hline & & \multirow{2}{*}{$\begin{array}{c}\text { 望虞河 } \\
\text { 望亭立交 }\end{array}$} & \multicolumn{4}{|c|}{ 太湖湖西主要人湖河道 } \\
\hline & & & 太滆运河 & 漕桥河 & 殷村港 & 陈东港 \\
\hline 2007 年 5 月 11 日一 7 月 4 日 & 55 & 3.43 & 8.65 & 8.95 & 7.23 & 6.00 \\
\hline 2007 年 7 月 20 日一 9 月 18 日 & 61 & 2.17 & 4.73 & 4.55 & 3.69 & 3.50 \\
\hline 2008 年 1 月 22 日一 6 月 8 日 & 139 & 2.86 & 9.87 & 9.19 & 7.25 & 6.13 \\
\hline 2009 年 4 月 27 日一 6 月 28 日 & 63 & 2.28 & 6.15 & 5.84 & 5.03 & 4.50 \\
\hline 2010 年 5 月 31 日一 7 月 5 日 & 36 & 2.42 & 4.63 & 4.25 & 3.56 & 3.96 \\
\hline 2011 年 1 月 1 日一 6 月 9 日 & 160 & 2.66 & 7.47 & 7.03 & 6.14 & 5.97 \\
\hline
\end{tabular}

表 5 望亭立交引水期主要湖湾水体总磷和总氮浓度

Tab. 5 Total phosphorus and total nitrogen concentrations of the main bays during the period of water diversion

\begin{tabular}{|c|c|c|c|c|c|c|c|}
\hline \multirow{2}{*}{ 时段 } & \multirow{2}{*}{ 时间/d } & \multicolumn{3}{|c|}{ 总磷/( mg/L) } & \multicolumn{3}{|c|}{ 总氮/(mg/L) } \\
\hline & & 贡湖湾 & 梅梁湾 & 湖西 & 贡湖湾 & 梅梁湾 & 湖西 \\
\hline 2007 年 5 月 11 日一 7 月 4 日 & 55 & 0.073 & 0.154 & 0.134 & 3.20 & 5.00 & 4.69 \\
\hline 2007 年 7 月 20 日一 9 月 18 日 & 61 & 0.082 & 0.224 & 0.205 & 1.96 & 1.64 & 2.92 \\
\hline 2008 年 1 月 22 日一 6 月 8 日 & 139 & 0.088 & 0.153 & 0.171 & 3.10 & 4.98 & 6.42 \\
\hline 2009 年 4 月 27 日- 6 月 28 日 & 63 & 0.051 & 0.070 & 0.060 & 2.15 & 3.58 & 3.59 \\
\hline 2010 年 5 月 31 日一 7 月 5 日 & 36 & 0.050 & 0.086 & 0.085 & 2.87 & 3.50 & 3.71 \\
\hline 2011 年 1 月 1 日一 6 月 9 日 & 160 & 0.063 & 0.057 & 0.134 & 2.63 & 2.56 & 4. 12 \\
\hline
\end{tabular}

\section{4 望虞河入湖水体总磷及可溶性总磷沿程变化分析}

为监测人湖水体总磷浓度人湖后的变化情况, 江苏省水文水资源勘测局无锡分局以望亭立交太湖内侧 点 200 (图 4) 为圆心, 向西呈扇形扩散, 以 300、600、900、1200、1500、2000 m 为半径布设水质监测站点, 每一 扇面上布设 5 个监测点, 最远在 $2500 \mathrm{~m}$ 的扇面上布设 2 个监测点 (点 231 、232), 监测站点布设见图 4. 于 2009 年 6 月 15-20日、2010 年 9 月 7-9 日、2010 年 11 月 28-29 日 3 次调水引流后期 $($ 共 $11 \mathrm{~d}$ ), 每天在布 设的监测点上进行取样监测, 监测的项目有: 水温、溶解氧、透明度、悬浮物、总磷、可溶性总磷, 以监测点 200 处的水质监测值作为望虞河引长江水人湖的水质值, 不同扇面上监测点的水质监测值代表长江水人湖后水 质的变化情况.

通过监测结果分析及绘制各次监测扇面上的总磷和可溶性总磷浓度均值分布图,可以看出:1）望虞河 引长江水人湖 $2500 \mathrm{~m}$ 处点 231 的总磷、可溶性总磷浓度比代表监测点 200 的要小,按每一扇面各点的多次 监测平均值计算, 平均降幅分别约为 $20.0 \% 、 21.3 \% ; 2$ ) 各扇面点上的总磷和可溶性总磷浓度监测值并非随 着距点 200 的距离增加而逐渐减小, 中间有一些监测点的总磷和可溶性总磷浓度会大些,这可能与监测点位的 底泥释放等因素有关,但总体趋势是距点 200 的距离增加, 总磷和可溶性总磷的浓度下降 (图 5 ).

虽然人湖水体中总磷的浓度略高于梅梁湾水体的总磷浓度、明显高于贡湖湾水体的总磷浓度 (表 3 和 表 5 ), 但水体人湖后水流速度显著下降,水体中悬浮颗粒夹带的含磷物质等迅速下沉. 实际监测也证明, 人 
湖后从望虞河人湖水体中的总磷和可溶性总磷含量比人湖前有明显的下降趋势, 总磷和可溶性总磷浓度每 千米约减少 $10 \%$.

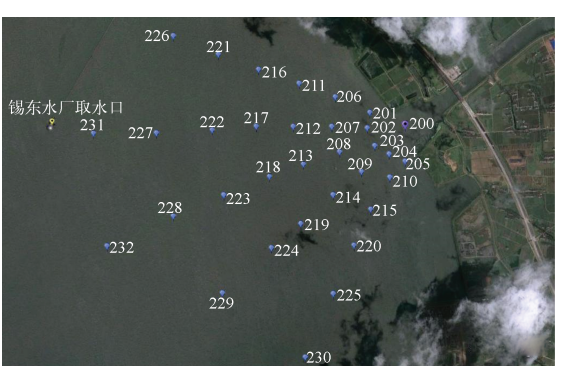

图 4 人湖水质总磷监测站点布设

Fig. 4 Distribution of monitoring sites for input total phosphorus

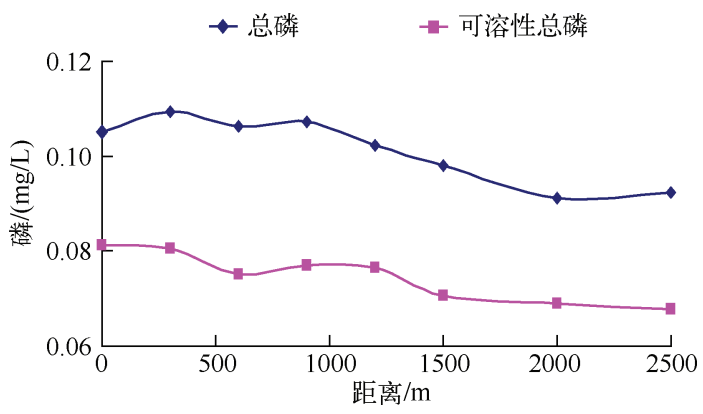

图 5 各扇面总磷、可溶性总磷平均浓度沿距离变化

Fig. 5 Variation of average total phosphorus and total dissoluble phosphorus concentrations with distance in each sector

\section{5 结论与展望}

1) 调水引流是当前应急改善太湖流域水环境的有效途径, 是通过流域水资源统一调度和优化配置进行水环 境改善的有意义、有效的探索, 实践证明持续调水引流对太湖梅梁湾、贡湖湾湖体水质的改善起到了积极作用.

2 ) 湖西主要人湖河道水体与望虞河人湖口水体总磷浓度比值的变化幅度在 $1.10 \sim 3.12$ 之间, 总氮浓 度比值的变化幅度在 $1.49 \sim 3.46$ 之间, 从望虞河引长江水人太湖, 人湖水体中总磷、总氮浓度明显小于太湖 湖西主要人湖河道水体的,长江水体水质明显优于太湖湖西人湖河道水体水质.

3 ) 在近年的调水引流期, 太湖湖西、梅梁湾、贡湖湾水体的总氮平均浓度分别是从望虞河引长江水人太 湖水体的 $1.72 、 1.34$ 和 1.02 倍, 太湖湖西、梅梁湾、贡湖湾水体的总磷平均浓度分别是从望虞河引长江水人 太湖水体的 $1.06 、 0.88$ 和 0.53 倍, 从望虞河引江人湖水体中总氮浓度要小于太湖湖西与梅梁湾水体的总氮 浓度, 基本与太湖贡湖湾水体的总氮浓度相当, 水体中总磷的浓度与太湖湖西水体的相当, 略高于太湖梅梁 湾水体, 明显高于太湖贡湖湾水体的总磷浓度.

4 ）实际监测成果分析表明, 望虞河引长江水人湖后总磷、可溶性总磷的浓度下降,每千米约减少 $10 \%$, 湖水对人湖水体中总磷和可溶性总磷有明显的吸附、降解作用.

5 ) 太湖水环境综合治理的措施很多, 除了调水引流外, 还有控源截污、蓝藻打捞、生态清淤等一系列措 施, 不可否认太湖湖体及湖湾水质有好转的趋势, 但具体某一措施的贡献是多少还有待进一步研究.

\section{6 参考文献}

［1］周小平,翟淑华,袁 粒. 2007 2008 年引江济太调水对太湖水质改善效果分析. 水资源保护,2010,26(1):40-48.

[2] 翟淑华,张红举,胡维平等.引江济太调水效果评估. 中国水利,2008,(1):21-23.

[ 3 ] 展永兴. 调水引流在太湖水环境综合治理中发挥的作用分析. 水利规划与设计,2010,(3):15-18.

[4] 展永兴,季轶华,沈 利. 调水引流在太湖水环境综合治理中的作用分析. 中国水利,2010,(4) :53-55.

[ 5 ] 秦伯强. 太湖生态与环境若干问题的研究进展及其展望. 湖泊科学,2009,21(4):445-455.

[6]许 梅, 任瑞丽, 刘茂松. 太湖人湖河流水质指标的年变化规律. 南京林业大学学报: 自然科学版, 2007,31 (6): 121-124.

[ 7 ] 贾锁宝,尤迎华,王 嵘. 引江济太对不同水域氮磷浓度的影响. 水资源保护,2008,24(3):53-56.

[8] 梁 斌,王 超,王沛芳. 复杂河网地区人河污染物调查分析和估算方法研究. 水资源保护, 2003,19(5):30-62.

[ 9 ] 郑 一,王学军,江耀慈等. 环太湖河道水质分析与人湖污染物负荷量估算. 地理学与国土研究, 2001, 17(1):40-44.

[10］马 倩,刘俊杰,高明远. 江苏省人太湖污染量分析 (1998-2007 年). 湖泊科学, 2010,22(1):29-34.

[11] 申金玉, 甘升伟, 陈 润等. 环太湖出人湖水量影响因素分析及对策措施研究. 水资源保护,2011,27(6):48-52. 